\title{
VOCABULÁRIO DE ENTRE DOURO E VOUGA
}

\section{ARTES DE PESCA MARITIMA}

Elementos para um Estudo Comparativo da Linguagem da Pesca de Portugal e Brasil

ARLINDO DE SOUSA

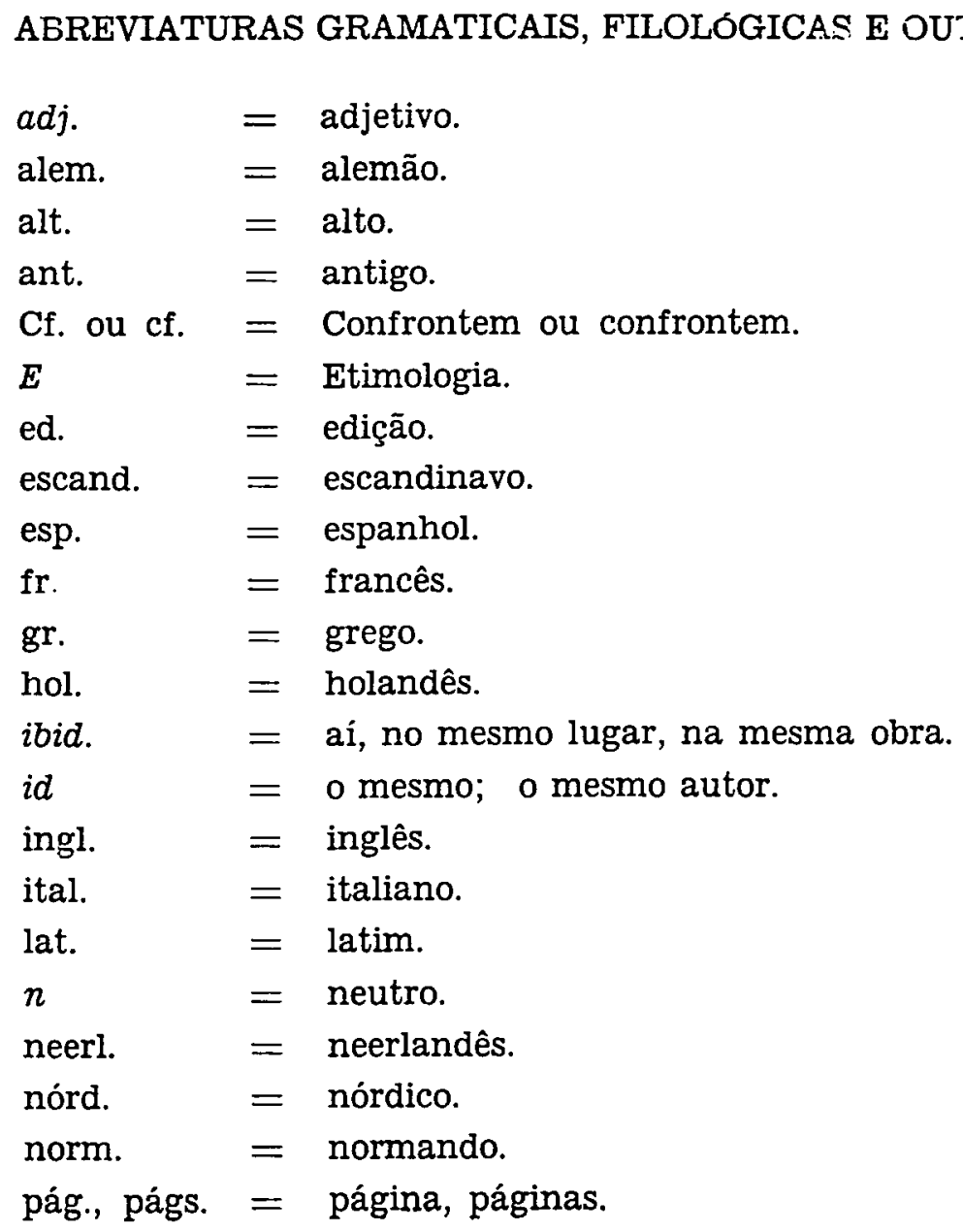


pl. $\quad=$ plural.

port. $\quad=$ português.

s.f. $\quad=$ substantivo feminino.

s.m. $\quad=$ substantivo masculino.

s.v. $\quad=$ no vocábulo, no têrmo.

v. $\quad=$ verbo.

v.g. $=$ por exemplo.

ABREVIATURAS DE AUTORES E OBRAS

$A$ Ria = Augusto Nobre - Jaime Afreixo - José Macedo, A Ria de Aveiro, Lisboa, 1915.

AABS, Pescas $=$ A. A. Baldaque da Silva, Estado Actual das Pescas em Portugal, Lisboa, Imprensa Nacional, 1892.

$\mathrm{AAC}=$ Antônio Augusto Cortesão, Subsídios para um Dicionário Completo (Histórico-Etimológico) da Lingua Portuguêsa, Coimbra, 1900.

$A D A=$ Arquivo do Distrito de Aveiro (desde 1935; ainda em publicação).

AM, $D E L L=$ Augusto Magne, Dicionário Etimológico da Lingua Latina, Rio de Janeiro (desde 1952: vol. I, A-Al, 1952; vol. II, AQ-CAL, 1953; vol. III, CAM-CI, 1953).

Bta $=$ J. A. Ferreira Baptista, no "Arquivo do Distrito de Aveiro".

CF = Cândido de Figueiredo, Novo Dicionário da Lingua Portuguêsa, 4. ${ }^{\mathrm{a}} \mathrm{ed}$. .

CGHP = José Joaquim Nunes, Compêndio de Gramática Histórica Portuguêsa, 2. ${ }^{a}$ ed., Lisboa, 1930; e outras ediçōes.

CM, Lições = Carolina Michaëlis de Vasconcelos, Lições de Filologia Portuguêsa.

Coelho = Francisco Adolfo Coelho, Dicionário Manual Etimológico da Lírgua Portuguêsa... Lisboa, s.d..

Correia, $U N=$ João da Silva Correia, Unhas Negras, Lisboa (1953 ou depois). 
Diez, Gram = Friedrich Diez, Grammatik der romanischen Sprachen; tradução francesa de Auguste Brachet et Gaston Paris, com o título "Grammaire des Langues Romanes", Paris, 1874.

Diez, $E W r S=$ Friedrich Diez, Etymologisches Worterbuch der romanischen Sprachen, Bonn, 1876-1877.

$D L C=$ Dicionario de la Lengua Española por la Real Academia Española, 15. a ed., Madrid, 1925.

Dozy = Dozy et Engelmann, Glossaire des Mots Espagnols et Portugais derivés de l'Arabe, Leida, 2. ${ }^{\mathrm{a}}$ ed., 1869.

Eguilaz = Leopoldo de Eguilaz y Yanguas, Glosario Etimológico de las Palabras Españolas (Castellanas, Catalanas, Gallegas, Mallorquinas, Portuguesas, Valencianas y Vascongadas) de Origen Oriental (Árabe, Hebreo, Malayo, Persa y Turco), Granada, 1886.

$E W r S=$ Vêde Diez.

$F E W=$ Wartburg, Walther von, Franzosischen Etymologisches Worterbuch... Bonn-Leipzig-Basileia (desde 1922).

FT $=$ Francisco Torrinha, Novo Dicionário da Lingua Portuguêsa.

$\mathrm{JS}=$ Jules Cornu, Die portugiesische Sprache, Separata do "Grundiss", de Grober, 2.a ed., 1904-1906, Estrasburgo, 1906.

Lokotsch = Karl Lokotsch, Etymologisches Woerterbuch der europaischen (germanischen, nomanischen und slavischen) Worter orientalischen Ursprungs, Heidelberg, 1927.

$\mathrm{LV}=$ Leite de Vasconcelos.

Melo $=$ Laudelino de Miranda Melo.

ML, Gram = Meyer Lübke, W., Grammaire des Langues Romanes, na tradução francesa de E. Rabiet Auguste e Georges Doutrepont, Paris, 1890-1904.

ML, Introd. = Meyer Lübke, W. Introducción a la Linguistica Romanica, tradução de Americo de Castro, Madrid, 1926. 
ML, $R E W=$ Meyer Lübke, W., Romanisches Etymologisches Worterbuch, Heidelberg, 1911-1920, 3.a ed., 1935.

Nunes $=$ José Joaquim Nunes.

$R E W=$ Vêde ML, $R E W$.

RL. = Revista Lusitana (desde 1887).

\section{INTRODUÇĀO}

Borda, pelo poente, a região douro-vouguense uma grande corda de mar.

São municípios marítimos: Gaia, Espinho, Ovar, Murtosa, Estarreja e Aveiro.

O território litorâneo foi habitado desde os tempos mais remotos.

Em Valadares e Lavadores, do município de Gaia, foram achados despojos do asturiense, pré-neolítico(1).

Tôda a região marinha, sabemo-lo, sobretudo, pela toponímia, viveu as civilizações das mámoas e das antas, do eneolítico, do bronze e do ferro; conheceu as brigas e as motas iberas, celtas e celtiberas; ergueu castros, vilas, casais, póvoas e fanos romanos; cultivou a cristandade de godos e suevos; plantou acistérios, capelas, ermidas, igrejas e mosteiros; e orou algo, também, pelo catecismo árabe ${ }^{(2)}$.

Nos documentos medievais, aparecem, muitíssimas vêzes, as expressões prope lit $(t)$ us maris, prope lit $(t)$ oris maris, etc., na demarcação das terras próximas, e, por vêzes, longínquas.

O mar estendeu a sua influência, desde as idades mais remotas, não apenas às terras à borda da água, mas até aonde se faz ouvir os seus marulhos misteriosos, nos dias tempes-

(1) - Arlindo de Sousa, Estudos de Arqueologia, Etnologia e História - Antiguidades do Municipto de Gaia: Civilizaçós Pré-Romana, Romana e Romano-Portuguêsa, Rlo de Janeiro, 1957, págs. 37-38.

(2) - Arlindo de Sousa, Onomástica Pré-Romana - a Propósito de Três Divindades Ante-Romanas da Regíäo de Entre Douro e Vouga, na "Revista de Portugal", vol. XXV, Lisbos, 1960, e separata; Toponimia Arqueológica de Entre Douro e Vouga, na revista "Letras", n.0 11, Curitiba, 1960, e separata, etc. 
tivos de verão, ou de inverno carregado, a vinte quilômetros da $\operatorname{costa}^{(3)}$.

De esqueletos de baleia são as traves e ripas das igrejas de Anta, Rio Meão e Canedo. Di-lo o povo.

A imbida, ou cordão umbilical, que os serranos de Arouca, Castelo de Paiva e Vale de Cambra enterram no solo, para que a criança que veio ao mundo, seja feliz, em Espinho, Ovar e Estarreja, terras marinhas, é lançada, com o mesmo fim, às águas do Oceano( ${ }^{(4)}$.

Crenças do mar bem diferentes, na verdade, das da ter$\mathrm{ra}^{(5)}$.

A língua, produto ambiental, acompanha os gostos da sociedade. Exprime o que o meio lhe oferece: o que é mar é mar; o que é terra é terra.

A alma de um pescador do Furadouro que não conhece outros trabalhos senão os da pesca, que canta os seus produtos nas lotas e pelos sete caminhos de Ovar, que reza e pragueja, pragueja e reza, e promete, cada ano, um círio da sua altura, ao Senhor dos Navegantes ou a São Cristóvão, para que os dois santos o livrem das fúrias das águas, quando está cão o mar, é muito diversa da alma de um lavrador de Vale de Cambra que, na doce solidão de seus campos, sob o céu duma longa abóbada, engorda o gado, amanha as vinhas, prepara os vinhos verdes, ordenha as vacas, fabrica queijos $\mathrm{e}$ manteigas, percorre as feiras, a encher de dinheiro fresco a

(3) - Cf.: "Tout cela plus sérieux encore dans les lieux voisins de la mer, qul y touchent sans la voir, qui n'en ont pas les spetacles, mals entendent sa grande volx. La terre déjà au repos, en silence, écoute les plaintes, les colères du viell Océan qui frappe, recule et refrappe avec des rimes solennelles. Basse, profonde qu'on entend molns de l'orelle que de la poltrine, qui heurte moins le rivage encore que le coeur de l'homme..." (J. Michelet, L'Amour).

(4) - Cr. A. Llma Carnelro, O Parto, no Arquivo de Medicina Popular, vol. II, 1945, pág. 35 .

(5) - Para o estudo da etnografia maritima, sāo fontes preciosas os fornais regionals, dos municiplos lltorâneos. Vêde, por exemplo, Arilndo de Sousa, Nossa Senhora da Ajuda de Espinho..., no Jornal do Commercio, do Rlo de Janeiro, de 12 de setembro de 1954. - Michel Bréal fala, era seu Essai de Semantique, da influéncla do mar na língua francesa, dêle vendo passar para as ativldades mais comuns levas contínuas de têrmos, sc., aborder, accoster, arriver, échouer, porter, etc.. 
carteira surrada, e sobe à serra de Castelões, a implorar graças à Senhora da Saúde.

E, se a gente das lavouras é Carqueja, Castanheiro, Gesteira, Mato, Moreira, Nogueira, Oliveira, Pereira, Pessegueiro, Pinheiro, Queirós, Salgueiro, Silva, Travaços, etc., a gente das marinhas, do moliço e da pesca é Areias (Espinho), Arrais (Paramos, Espinho), Bacalhau (Espinho), Bargão (ibid.), Barqueiro (Ovar) ${ }^{\left({ }^{(0)}\right.}$, Bitchelo ou Bichelo (ibid.) ${ }^{(7)}$, Bóia (Espinho), Cação (Murtosa e Ovar), Camarão (Ovar), Carangueija (ibid.), Carangueijo (ibid) ${ }^{(\mathrm{s})}$, Carapau (Espinho), Caravela (Murtosa), Faneca (Ovar), Faneco (Ovar, e Silvalde, de Espinho) ${ }^{(0)}$, Fatoco (Espinho), Fragateino (Ovar e Aveiro), Inguião, por Enguião (Ovar), Lapa (Espinho), Marinheiro (Espinho e Ovar), Mergulhão (Ovar) ${ }^{(10)}$, Muge (Silvalde, de Espinho), Navalhinha (Murtosa), Patrão (Espinho), Peixe (ibid.), Peixegoto (Ovar), Peixinho (Aveiro e Espinho), Perdido (Espinho) ${ }^{(11)}$, Pitéu (ibid.) ${ }^{(12)}$, Pitinga ou Petinga (Ovar), Raia (Ovar e Espinho), Ré (Ovar), Rêdes (ibid.), Redilheiro (Espinho) ${ }^{(13)}$, Roivaco (Murtosa), Rubalo (Ovar)!14), Ruibo (Espinho), Safa-a-Rêde (Murtosa), Salmonete (ibid.), Sardinha (Ovar e Estarreja), Sardinha (Ovar e Estarreja), Sardo (Pardilho e Bunheiro, de Estarreja), Sável (Murtosa), Solha (Ovar), Tainha (ibid.), Tarrafa (ibid.), Truta (Espinho), Zarrais, em vez de Os Arrais (Silvalde, de Espinho)(15).

(6) - Ano de 1693. Vêde Pe. Manuel Lírio, Passos de Ovar, pág. 106.

(7) - o mesmo que mexilhão. A sonâncla $t c h$, em vez de $c h$, é multo vulgar na reg1åo douro-voguense. Estudamos, muito desenvolvidamente, a fonética de Entre Douno e Vouga em nosso Vocabulário de Entre Douro e Vouga Subsidios de Geografia Lingilistica para um Atlas Geral da Lingua Portuguêsa, vol. I. Introduçăo.

(8) - Ano de 1717. Vêde Pe. Manuel Lírlo, op. cit., pág. 108.

(9) - O Faneco, de Ovar, é de 1873. Vêde id., ibid., pág. 116.

(10) - Ano de 1695. Véde id., ibid., pág. 106.

(11) - Individuo :que fol, mllagrosamente, salvo de morrer afogado.

(12) - Corxesalna de pescadores.

(13) - Fabricante de rêdes.

(14) - Ano de 1699. Vêde Pe. Manuel Lírio, op. cit., pág. 106.

(15) - Cr., a respeito da antroponimia inspirada pelo mar, Alain villers: “...The man fishes and the womsn sells, and fish are so much a part of their lives that their very surnames come from Iish. In Nazare it is Mr. Bonita, and Mrs. Bream, young Master godfish, and his cousin Miss Haddock; nor does it strike anyone that there is anything incongruous in the naIres" (Golden Beaches of Portugal, in The National Geographic Magazine, November, 1954, p. 680). 
E o mar inspira topônimos: Costa do Mar, Francelos ${ }^{(16)}$, Marinha, Miramar, Praia da Granja, etc.; títulos de casas comerciais: Casa Mar, Mar Alto, Mar e Sol, Tá Mar, etc.; 10cuções interjetivas: êle ai vai agarrai-o(1i), vira de escota! ou vira ao norte!, com a significação de "retira-te!"; imprecações: o mar te coma!, o mar te leve!; pregões: belo gruaz! (18), merque enguias!; rifões: bota para a bateira (aliteração), raia, em maio, tumba à porta, etc.; falares rimados: a raia faz cair a saia, homem do mar cabeça no ar, sardinha de são-joão pinga no pão, etc.; comparações: magro como um peixarenho, salta como uma sardinha, etc.; tropos (metáforas, sinédoques, ironias, metonímias): anzol, na expressão deitar o anzol, isto é, procurar atrair ${ }^{(19)}$; bacalhau, mulner magra; cf.: "Tôda a palha enche palheiro, / Todo o fiado faz pano... / Quem casa com mulher magra / Tem bacalhau todo o ano"; e apertar o bacalhau, apertar a mão; e, ainda, pesar bacalhau, cabecear com sono; cação, pessoa travêssa, irriquieta, folgazã, maldosa, velhaca, etc., qualidades tôdas tiradas do cação, peixe; alcunha, já em 1676, um João Pereira Cação com pai e avô também Caçāo(20); carangueijola, nome gracioso dado às primeiras caminhetas que começaram a circular ${ }^{(21)}$; caranguejeira, qualidade de ameixa grande e da côr dos carangueijos; escota, na expressão ter a escota na $m a \tilde{o}$, ter o govêrno ou o seguro na mão(22); faneca, na expressão pintar a faneca, praticar diabruras; fateixa, na expressão deitar a fateixa, atrair, aliciar ${ }^{(23)}$; fatoco, indivíduo baixo;

(16) - Francelo é o nome de uma ave maritima. Cr. o rifăo povelro (de Póvoa de Varzim): "Francelha à praia, sinal de pelxe". Em nosso Vocabulírio, vols. II e III, poderāo ver-se outros nomes de aves aquáticas: alcatraz, arau, buzo ou buzio, cagarra, franga-ribeirinha, gaivina, gaivota, galego, galo-da-ria, gatragina, gavinha, grual, gruleta, guarda-rio, guarda-rios, lavanco, narja, negra, painho, pardela ou pardelha, pita-da-água, pita-dorio, rabacoelha e viuiva.

(17) - "Ell'aí bai, agarrai-o", ne fonética varelra, espinhense: versos que os pescadores recitam ao butar pró mar o barco. As expressర̋es, a seguir, sáo, assim, pronuncladas: bira de scota! e bir'o norte.

(18) - o mesmo que goraz.

(19) - Cr. Cicero: "homines capiantur, ut pisces" (De Senectute, XIII).

(20) - Vêde Arquivo do Distrito de Aveiro, vol. XV, pág. 216.

(21) - Joäo da Stlva Correis, Os Outros, pág. 272.

(22) - Vède o texto: "Enquanto eu fôr vivo, êles náo fazem o que querem, porque eu é que tenho a escota na mäo" (Arlindo de Souss, Vocabulario...., vol. II, de J. A. Ferreira Baptista, no ADA, XIV, pág. 35).

(23) - Joh́o da Sllza Correla emprega a expresś̆o em Unhas Negras, pág. 268. 
diz-se, também, fatoquinho; guarda, parte da rêde que reforça o saco; mar-bravo, pessoa que se irrita e abrandece com facilidade(24); pescar, atrair, conquistar(25); observar, entender, compreender ${ }^{(26)}$; poitar, pousar; rêde, na expressão estender a rêde, procurar atrair ou cativar; cf. o latim tendere retia( ${ }^{(27)}$ e o francês tendre les filets; ainda: não enxugar a rêde, andar sempre bêbedo( ${ }^{(28)}$; rer, na expressão rer contas, fazer contas, acertar contas ${ }^{(20)}$; salear, trabalhar ${ }^{(30)}$;

(29) - Vêde o meu Vocabulário..., vol. III, onde damos mals: mar, área de água dentro do mar: "Os pescadores encontraram, hoje, um pedaço de mar ruim": vaga, onda, conjunto de ondas; pântano, lagoeiro de águas pluvials; tamibém Já em Isidoro: "Omnis congregatio aquarum abusive maria nuncupantur". (Etymol. sive Orig., XIII, 14); cr. o francês mare; imensidáo, profusáo, grande quantidade: um mar de ltvros, um mar de gente; também, no francês, $v$. g.: “... des bouleaux agités par les brises et dispersés çà et là formalent des les d'ombres flottantes sur cette mer Immoblle de lumlère" (Chateaubriand, Génie du Christianisme); poente: "Vermelho ao mar, velhas a solhar" (solhar, apanhar sol); andar ao mar: andar exa serviço de pesca (barco, pescador, etc.); correr o mar e a marinha: andar de seca em meca; andar de um lado para outro; mar-de-banco, local onde as ondas começam a formar-se; mar-deterra, mar próximo à costa.

(25) - "O Zé da Mata anda a ver se pesca a Maria da Viúva". Cf. o arrifanense [de Arrifana, mun. da Felra] quinhentista, Pe. Gonçalo de Ollvelra: "Anda agora nesta casa aprendendo a doutrina, pera com êle pescarmos outros multos..." (Curta a S. Francisco de Borja, escrita do Rlo de Janelro, em 21 de malo de 1570, ap. Pe. Serafins Leite, Paginas de História do Brasil, págs. $39-46$ ).

Emprega-se, com a mesma signiflcaçro de pescar, fisgar.

(26) - "Todos pescaram a coisa".

(27) - Martialls, Epigr., II, 27.

(28) - "O Eurico anda sempre bêbedo. Aquêle nunca enxuga a rêde" (J. A. Ferreira Baptista, op. cit., XIII, pág. 196).

(29) - "Tu pagaste umas despesas, e eu paguel outras. Agora, é preclso rer contas" (id., ibid., XIV, pág. 32).

(30) - "O simáo é multo trabalhador. Nunca está parado, anda todo o dia a salear" (id., tbid., XIV, pág. 33). O vocábulo liga-se no latim sal, sal. Como salear é têrmo da reglío das salinas de Avelro, de um melo em que a ocupaçáo dominante se relaclona com o sal, năo admira que salear torsasse o sentido geral de "trabalhar", espectalizando a sua signiflcaçá. Nos municípios, longe do mar, da Feira, Gala (fregueslas do interior), Arouca, Vale de Cambra e Castelo de Paiva, costuma dizer-se, principalmente, quando se está no domingo, a propósito da segunda-felra: "Vamos descansar hoje, que, amanhá [segunda-felra] é dia-de-pica-bot. Trabalhar, por sua vez, parece provir de *tripaliate (de *tripalium "tronco de ferrador") "trabalhar num tronco de ferrador", passando a exprimir "fazer qualquer espécle de serviço". O espanhol diz trabajar, o 1taliano travagliare e o Irancês travailler.

Muitos outros têrmos das marinhas ou salinas de Avelro podem ser vistos em nosso Vocabulário...: algibé, andaina, andoar, apancar, balde "pequena pá", baldeaçâo, baldear, baracha, barrento, bomba, bulir, cabeceira, saldeiro, cambeia, camisa-dos-meios, cercear ou circear, cfrcio, coalhar, comedoria, curar, eira, imoirar, limonio, malhadal, manaia. mandamento, marinha, marinhāo, marnoto, meio-da-marinha-nova, meio-da-marinhavelha, mercantel, picante, picar, polme, rasolla, rasoira, redar, redrar, re- 
sardinha, bofetada, jôgo infantil; toninha, pessoa baixa; traste, banco dos remadores e pessoa ordinária; velar ${ }^{(31)}$, botar a vela ao ar para o barco andar, e deslizar qualquer barco, na água, mesmo sem velas ${ }^{(32)}$.

$\longrightarrow: 000:$

A linguagem de pesca de Entre Douro e Vouga não se restringe apenas aos vocábulos que, abaixo, damos, separadamente, de artes marítimas.

\section{A pesca douro-vouguense comporta uma terminologia muito rica que pode ver-se em nosso "Vocabulário..."(53):}

dura, rer, rido, rodar, ródo, safra, sainete, sainha, sainho, sal, saläo, saleiro, salineira, salina, salitre, salmoira ou salmoura, sobre-cabecetra, tabuleiro, talho, tamadoiro, viveiro e zorra, pelo menos.

No Vocabulário... damos, também, multos têrmos da vegetaçăo marinha de Rla de Areiro e Lagoa de Esmoriz princlpalmente, de plantas moles, conhecidas pelo nome coletivo moliço, precloso adubo das terras: alface-ãomar, arganel, carqueja, carrapeto, cártega, castanhol, ceva ou seba, cirigo ou cirgo ou, ainda, sirgo, corozil, fita, folha, folhada, gorga, langanho, limonio, mormaça, mormo, morraça, papeira, pinheira, pojo, rabo, tabua, trapa, etc.. O trabalho de apanha ou colhelta do moliço possul, também, uma terminologia rica: arrastar, gadanha, manejo, mariscar, matola, moliceiro, rapāo, etc.. Náo é tudo, a respeito das plantas aquáticas. Sob outros aspectos: bajunça, barcinha ou bracinha, boleira, bruco, bugalho, çabarrinha ou sabarrinha, canizia, castanho, cordeirinho, cortiço, embude, escalracho, estramagueira, golfe, junça, labaçol, macaca, marinhão (vendedor de Junco), nadabau, patinha, rapilho, sazeiro, solda ou sorda, etc.. Nao devemos esquecer a linguagem das estelras de bainho, bunho ou buinho dos obreiros de cavalo à porta (os-de-cavalo-d̀-porta ou veirenses) de Velros, munlciplo de Estarreja.

(31) - Na tonética varelra, de Esplnho, diz-se bular: "Aquêle barco qui bulou de lá é o do zé Zarrais".

(32) - Vêde muitos outros fenômenos de linguagem trópica marítima e rural cm nosso Vocabulário...

(33) - Vocabulario de Entre Douro e Vouga. Subsidios de Geografia Lingilistica para um Atlas Geral da Lingua Portuguèsa. Cơmpóe-se de três grandes volumes: vol. I. Introdução; vol. II. A-J: vol. III. I-Z.

A Introduçāo está dividlda em sels partes:

A 1." Parte contém os capitulos "Vista Geral da Regiåo"; "Da Criaçăo de Museus de Linguagem Regional"; "Fontes da Língua"; e "Critérlo a que obedeceu a recolha dos Vocábulos".

A 2." Parte diz respelto i fonética.

A 3. Parte comporta a morfologia, entre outros assuntos, os gêneros, números, categorias gramaticals, vozes dirigidas aos animals, conversas atribuidas aos animais, vozes dos sinos, composiçăo, derivaç̧o, etc.

A 4.: Parte é referente à estilistica: contribuiçōes terrestre e maritima; elementos gerais; alteraçరes; lalares rimados; Irases estereotipadas; superlativaçoes; fómmulas de tratarrentos; saudaçós, despedidas, agradeclmentos; Juramentos; comparaçōes com os animals, vegetais, etc.; linguagem maliclosa: cacófatos, alusóes aos órgåos genitals e atos sexuals, aberraçరes, Infidelldades conjugals, etc.; anexins; parêmtas; sentenças; 
abanhar, abarga, abicar, abrir, adague, aguagem, agulha, ala!, alar, albitânea, alcadoeira, alcanela, alcatruz, alto, aluzar, alvitana, amanhar, amarra, amarrador, amarrilho, ancoro, andaço, andaina, andar, na expressão andar ao frago (o peixe), anete, anga ou angra, angeijāo (vento), angelina, anzol, apertar, apoitar, aranha, aranhô, arau, arco, arda, ardido, areiinho, arinque, armado, armar, armela, arraia, arrais, arraisda-terra, arrais-do-mar, arrastão, arrastar, arrasto, arrebentação, arrebentação-do-mar-de-banco, arrebentação-de-terra, arremedilho, arricável, arrolar, arte-da-giga, arte-grande, arte-nova, arte-pequena, arte-velha, aselha, assais, atador, atafais (utensílios de pesca), atar, atensão (= tesão), aterrear, atonado, atonar, avio, azagaia, babeira, babujar, babuge, baia

rifōes; irontas; maledicênclas, etc.; tropos: metáforas, sinédoques e metonimlas; eufemismos, referentes a atos de agressáo, a animals, corpo humano, defecar, nojo por alguém, diabo, diarréla, doenças, embriaguez, vebldas, mjenstruaçáo, morte, onanismo, para afastar alguém, para mandar calar alguém, prenhês, roubar, para encobrir palavras obscenas ou cuja pronúncia provoque efeitos desagradáveis, cadeia, ventos intestinais, relaḉes sexuals com respelto ao homem e à mulher; disfemismos; trocadilhos, etc.

A 5.: Parte trata de onomástico: de toponimia e antroponimia. Topontmia: topónlmos provenlentes da constltulçăo geológlca; hldrografla; configuraçăo do solo; vegetaçáo; fauna; agregados populacionals romano-portuguêses; construçōes ou institulçóes civis ou soclais, comercla1s, industrlals, religlosas, políticas e mllitares romano-portuguêsas; profissóes; agricultura; fam;lia; religiáo cristâ ou náo; viaçáo; clima; fogo; côres, etc.. Antroponimia: nomdes oftclais, apelidos, alcunhas, etc.. Alcunhas individuals, famillares e coletivas. Alcunhas ligadas a acontecimentos diversos: defeitos físicos; estados Inferiores da alma; palavras mal pronunciadas; ditos; estatura; côr da pele, olhos, cabelos, etc.; distınçáo de famillas; trato; vestuárlo; profissós; sabedoria real ou aparente; emlgraçăo; desprêzo; povoaçōes, etc.. Alcunhas de bols, cães, gatos, cavalos, etc.

A 6." Parte trata de "Povoamento Medieval da Regía", em relaçáo com o povoamento pré-romano e romano-godo-árabe, e em relaçáo com o presente. o volume II (A-J) e o volume III (L-Z) sáo do vocabulário geral da regláo. Mals de 10.000 vocábulos, grande parte dêles ainda náo dicionarızada nos malores léxicos da língua, ou dicionarlzada, mas náo coma as signiffcaçరes al achadas. Valorizam o "Vocabulário" muitos estudos de ordem semântica, etimológica, etc.. A obra contém, ainda, preclosas informaḉes dt caráter arqueológico, etnológico, soclológico, etc..

Já falamos dêste assunto no Jornal do Commercio, de 6 de março de 1955, num longo artigo de apresentaçáo do "Vocabulário" ao público brastleiro Interessado. Neste artigo, demos o texto quase integral do capitulo "V1sta Geral da Regláo de Entre Douro e Vouga" da 1. Parte da Introduçáo. No mesmo jornal, número de 9 de abrl1, mesmio ano, demos o texto do capítulo "Da Criaçáo de Museus de LInguagem Reglonal", no número de 7 de agôsto, o texto do capítulo "Fontes da Língua"; e no número de 11 de setembro, o texto do capitulo "Critério a que obedeceu a Recolha dos Vocábulos". Todos os textos sáo da 1." Parte da Introduçáo. 
(porção de água mansa que fica entre o mar-do-banco e a $a r-$ rebentaçāo-de-terra), baleia, baliza, barbal, barbisco, barbo, barcaça, barbagão (também dito berbigão, berguigão, breguigão e briguigão), barga ou varga, barquear, barqueiro, barra (substantivo e adjetivo), barria, batedouro, bateira, batelada, bateleira, beijinho, beliscar, berbigoeira ou berguigoeira, besugo ou vesugo, bica, bichata, bicheiro, bichelo, bichoiro, bisame, biu-biu, boça, bocada, boga, bóia, boiar, bolear (=velar e velear), bôlo, bolsa, boqueirão ou biqueirāo, borbulhido, borda, borda-falsa ${ }^{(34)}$, bordada, bordão, bôrdo, bota-abaixo, botirão, botiroeiro, bôto, braça, branco, branqueira, brasino, brear, breçolho (ou bressolho?), bruxo, bugiganga, burel, burgau ou gurgau, burgo, burrica, buzo e búzio, cabaceira, cabaço, cabeça, cabeceiro, cabeleiro, cabra, caçadeira, cação, cachiço, cachopo, cachote, cacife (ou cacifo, cacifre e cacifro), caçoeira, cadino, cadoura, cágado, cagarete, cagaréu, cagatoino, cair (tornar-se o mar bom para a pesca), cal ou cale, cala, calamāo, calamento, calão, calar, calcadeira, caldear, caldeia, caldeirada, cale, calimba, calime, calimeira, calmeira, camarada, camaräo, camarinha, camaroeira, cambada, cambāo, cambar, cambeia, cambo, camboa, campanha ou companha, cana, na expressão botar à cana, candear, candeio, caneiro, caneta, na locução à caneta, canjar, cano, cão, capela (onda alterosa), capelo, caqueiro, caracol, carangueijo, carangueijola, caranguejeira, carapau, caravela, cavalo (corda), caverna, cavernil, cego, cêrca, cêrco, chã, chalandra, chamador, chanfana, chão, charolo, chato, chávega ou xávega, chelão, cheleira, chelote, chibeira, chicote, chilreira, chincha, chincheiro, chinchorro, chocho, na expressão em chocha, choco, chousa, chumaceira, chumbada, chumbeira, chumbeiro, chumbo, ciba, cofo, colher, comeira, companha ou campanha, concharinha congro, copejada, copejadura, copejar, copo, coqueiro, coral, corda (litoral, linha da costa), corrículo, corrimão, cortiçada, costado, cota, côvão, côvado, covo (= cofo), crena, crenar, crica, croque, cuada, curral, currinhal, derra-

(34) - Damos alguns têrmos de barcos e aparelhos de peaca do rlo Douro e, por extensáo, de barcos de conduçåo de passageiros e mercadorias, incluindo os barcos-rabelos, Igualmente, do rio Douro, de mercantéls dos $\mathrm{HOS}$ Vouga e Agueda e de mollcelros da ris de Avelro. 
balho, desalvitanado, desenrascar-se, desmalmado, despescar, dinheiro-do-mar, draga, eiró e eirô, emalhar, embergue ou envergue, embude, empatar, encalhar, encandear, encanteirar, encaranguejar, encascar, encasque, encher, encorar, encurta, encurta-do-maião, enfarruscado, engalhar, engalriçar-se, enguia, enjoar (cheirar mal o peixe), enrabiscado, enrascada, enrascadela, enrascadura, enrascanso, enrascar-se, enredador, entepara, entralhar, entralho, entremesa, enxido, enxugar, na expressão enxugar a rêde, escalamão, escamão, escamarão, escamento, escasseiro, escasso, escoadoiro, escoar, escochado, escochar, escochente, escota, esganar, na expressão esganar as palmas, esgocho, esgotadouro, esgôto, esmalhado, esmalhar, espadela, espadilha, espanar, especo, espelho, espetada, espia, espiador, espicha, espinhel, estaca, estacada, esteio, esteira, esteiro, estramagueira, estrebulir, estribeira, estripar, estrobar e estrovar, estrôbo e estrôpo e ainđa estrôvo, falca, falquear, faneca, faticeira, fateixa, fatoco (faneca pequena), fatoquinho, feitio (indicio de peixe), principalmente, na expressão procurar o feitio, fêmeo (masculino de fêmea), ferragem-de-fora, ferrar, ferruge, finco, fisga, fisgada, fisgão, fisgar, fisgar-se, fioda (peixe-agulha), foição ou foução, forcada, frago, funda, gaiuta, gaivina ou gavina (ave que indica feitio, isto é, que é indício de peixe no mar, assim como outras, sc., alcatraz, arau, gaivota, painho, pardela ou pardelha, etc.), galga, galinha-do-mar (tremelga), galiota, galo, galricho, gambuzilho, ganapáo, ganapo, ganhuço, ganilho, ganizo, garatéia ou gratéia, garôto (peixe ainda novo, por criar), garragina, garranto, gasgote, gavina, giga, grafião ou gulfião e, ainda, gurfião, gratear, grota, grumo, guarda, guelra, guia, guieira, guincho, gurgalhada, gurgau, ilhalvo, ingalhar, isca ou isco, janeira, jeito, labaça, laço, lacraia e lacrau, lago, lampreeira ou lampreeiro, lançamento, lance, lanço, lapa, laracha, largadouro, larote, lastro, lavada, lestada ou lestrada, lingua, lingueirô, linha, loda, loira, lula, luzo, maçadia, macola, maião, majoeira, malaia, malecueco, malhagem, manaça, manaia, mansidão, mandante, manga, manta, mão, mar, marde-banco, mar-de-terra, marabota ou maragota e, ainda, margota, maré, marear, mareiro, marezia ou marzia, maria-pica, marinha, marinhão, marnoto, maxoalho ou meixoalho e, ain- 
da, mexoalho, mercantel, mercantela, metedor, mijona (arraia pequena), mileras, milharas, milheras ou mirulas, mocidade (carapau ainda menor que a petinga ou sardinha pequena), modo, môsca, mosquear, mouro, mudador-de-madeira, mugiganga (= bugiganga), mujeira, muleta, muno, nassa ou nasso, navalhinha, navegante (crustáceo), negrāo (pei$\mathrm{xe})$, negrol (substantivo coletivo: cardume de sardinhas), nordestão, noroestão, nortada, norte, olho-de-boi (vento), olho-verde (peixe), orla (orla), onda (ornato de bordados vareiros), orçar, ouca, ovado, pail, paixão, palangre, palheiro, palma, palmeiro, panca, panda, pandeireta, pandulho, paneiro, pano, pardela ou pardelha, parreira, passador, pataleta, pegadouno, pego, peija, peixão, peixarenho, peixe-branco, peixe-de-escolha, peixe-de-fundo, peixe-pau, peixe-sapo, peixeira, peixinho, pendão ou pundão, pescada, nas expressões arrastar a pescada e arrotar postas de pescada, pescadeira (feminino de pescador), pescado, pescar, pescarejo, pesqueira, petinga, pia, pião, pica, picado, picar, pichorro, pimpão, pipo (= calime), pique, pitau ou pitéu, pluma, poita ou pouta, poitar ou poutar (cf. apoitar), pontal, proa, procurador, proeira, punda, pundāo, punho, puxador, quarteirão, rabeiro, rabeta, rabo-de-galo, ração, raçoeiro ou reçoeiro, raia, raião, rapichel, rapilho, rasca, rascaço, rascão, rasco, rastolho ou restolho, recachia, recoleta, reda, rêde, redeiro, remadoira, remadoiro, remar ao cano, remar à espia, remar a três de pé, rêmo, rêmomaião, rêmo-proa, requinte-do-maião, requinte-da-proa, resulho ou rosulho, retenida, ribeira, ricavém, rinzar, rinze, risca!, rize, robaleira, robinegra, roda, rodeiro (têrmo dos barcos-rabelos), rôdo, rola, na locução à nola, roubaco ou rouvaco e, ainda, roibaco e roivaco, ruiva, ruivaco, ruivo, sacada, saco, safio, safra, sagrado, na expressão mar sagrado, sagro, saguncho, saitela ou seitela e, ainda, sertela e sertelha, saleiro (peça de madeira que une as duas tábuas do sagro a que se sobrepõe, em barcos do rio Douro), salmoira ou salmoura, salmonete, saltāo, salto, sapo, sardinha, sávara, saveira, sável, savelha, savelhinha, savoga, savolho, sediela ou serdiela, seitelar, selha, semino, serteleiro, sil, singeleiro, sirga, sirgagem, sóbre-vara, solha, solheira, suestão, sueste (boné de lã muito grossa e abas compridas), sul, surdir, taburno, taco, tala, ta- 
lista, tareco, tarembeco $(=$ tareco $)$, tarma, teca, tendal, terlinga ou trelinga, termina, tesão (cf. atensäo), ticum, tintureira, toalha (cardume de peixes; cf. negrol), tolete, toloca, tomar (= pescar), toninha, torteira, tosamento, toste, toutiço, tralha, trancar, traste, travessia-alta, tremalho e tresmalho, trempe, trilha-pé, trinca-espinhas, trincada, troses (calças dos vareiros), truita e truta, uje, unha, unhante (pescador da Ria de Aveiro que apanha as enguias à mão), vai-e-vem, vara, varadouro, varal, varar, varela, varestilha, varinha, vareirada, vareiro, varga ou barga, varina, varino, vasculho, velar e velear (= bolear), verdugo, verga, vermelho (qualidade de camarão), vilão, viloa, vir, na expressão vir o mar a bom (cf. cair), xávega ou chávega, e zagaia.

Estudaremos, primeiro, os vocábulos que se ligam às artes velhas e novas de pesca marinha: barcos e aparelhos. Deixaremos para outra oportunidade as artes fluviais.

Os velhos dizem que se avizinha o mundo de Anti-Cristo, das profecias.

O século vinte surge como um grande túmulo das belas crenças do passado.

O que é velho morre, mas morre devagar, não com a intensidade e ritmo atômico dos nossos tempos.

Rasgam os campos da cultura popular novas bêstas apocalípticas.

Salve-se o que ainda possa ser encontrado(35).

Revigorem-se as tradições esmorecidas.

Acorde-se o que esteja adormecido.

A procura de belezas imersas revolva-se, até, o fundo dos náufragos perdidos.

Todo o esfôrço espiritual tem em si mesmo a recompensa: a alegria e a felicidade dêsse esfôrço.

(35) - O antigo vocabulário da pesca está a perder-se totalmente com a introduço de artes novas (arrastóes, traineiras, etc.), adventłclas, que vêm substitulndo as velhas. Com o abandono dos antigos processos de pesca está-se perdendo, taribèm, uma grande riqueza etnográfica. 


\section{ARTES DE PESCA MARITIMA}

ABICAR, $v$. I. Aproar um barco de pesca à praia. II. Terminar em bico. Vêde Botirão. $E$. Vêde Bica.

ABRIR, $v$. Alargar-se ou espalhar-se um cardume de peixe. Vêde Pião. E. Do lat. aperire.

ADAGUE, s.m. Vêde Parreira.

AGULHA, s.f., I. Utensilio de madeira ou de metal, para fazer ou consertar rêdes. II. Ponta aguçada da madeira do bôrdo e fundo dos barcos. III. Vêde Camaroeira, Espinhel, Pica e Trempe. E. Do lat. acucula < acus < acere, "ser azedo".

ALA!, interj. Voz proferida pelos pescadores, ao puxarem o barco ou as rêdes para terra. E. Vêde Alar.

ALAR, v. I. Puxar a bateira ou o barco da companha, pela areia arriba, por meio de rolos. II. Puxar a rêde ou outros aparelhos de pesca para terra; ir, caminhar: "Ala que se faz tarde"; "Ala, ala, meu cavalo, / Vai-te desaparelhar. Vai levar novas à tia / Que me venha cá buscar" (de um romance popular).

(Continua)

(36) - Acucula, por acicula, vê-se em certos manuscritos, ap. Dlez, Gram, I, 4. 